\title{
3D design of machine for gypsum hollow brick based on UG
}

\author{
Weifeng $\mathrm{Ma}^{\mathrm{a}}$, Sicong Yuan ${ }^{\mathrm{b}}$ and Xing $\mathrm{Liu}^{\mathrm{c}}$ \\ Mechanical and electrical engineering college, Xian University of architecture and technology, Xian \\ 710055, China \\ a1069334050@qq.com, bysc_3c@163.com, '345077588@qq.com
}

Keywords: gypsum hollow brick, forming machine, UG, visual assembly.

\begin{abstract}
Machine of gypsum hollow brick is a special machine equipment for making gypsum hollow brick. To improve design efficiency of the gypsum hollow block forming machine, shorten the product design and development cycle, meet the needs of medium investors and product upgrading, enable enterprises to quickly respond to market demand. According to the structural characteristics and working principle of gypsum block forming machine, three-dimensional solid model, virtual assembly design and motion simulation of a gypsum block machine were realized by parametric design and motion simulation based on UG 3D software. It improves design quality, facilitates optimal design of forming machines, and helps to enhance product development capabilities.
\end{abstract}

\section{Introduction}

Preparing industrial by-product gypsum a lot in our country, such as phosphate rock phosphate after the rest of the slag, the slag can not get the comprehensive utilization for a long time, also caused serious pollution to the environment. In order to cycle the use of national resources, waste, gypsum block project is one of the best ways to solve this problem. Gypsum block as building wall materials, has many advantages, the main is energy saving, lightweight, fast construction speed, high construction quality. But because of long, gypsum block production equipment not only small in our country, and most of the imports, individual domestic equipment is expensive, low level of technology, performance can't satisfy the requirements of the gypsum hollow block mass production, the gypsum block this kind of wall material has been widely used in a developed country is difficult to promote $^{[1]}$.

As the global machinery and equipment market competition is increasingly fierce, shorten product development cycle has become one of the important means of competition, is also the important guarantee of manufacturers to grasp the opportunities for advantage. UG is a Windows based $3 \mathrm{~d}$ modeling software, through which can carry out $3 \mathrm{~d}$ part design and $3 \mathrm{~d}$ virtual assembly, are free to change the design data, in computer products, such as process design, analysis and processing, the design of the product so as to shorten the development cycle, reduce design cost and established the foundation for the future development of new products innovation model, therefore they are widely used in product design and development.

\section{Gypsum hollow block structure analysis}

Gypsum hollow block is a kind of high performance building wall materials, fire, light weight, heat insulation, high strength, can adjust air humidity sawing, drilling, etc. Block there are many types of specifications, four side has concave and convex tenons, the former Soviet union called mortise type gypsum board, called the gypsum partition board in Germany. Gypsum hollow block shape is simple, easy to masonry, laying pipes inside the hole to facilitate. ${ }^{[2]}$ Square hole brick can reduce weight, suitable for the square hole filling of thermal insulation material, sandwich block, the disadvantage is that mold release is not convenient. Modelling of round hole brick is not easy to damage, it's convenient to make casting molding core-pulling, round hole gypsum hollow block brick structure as shown in figure 1. 


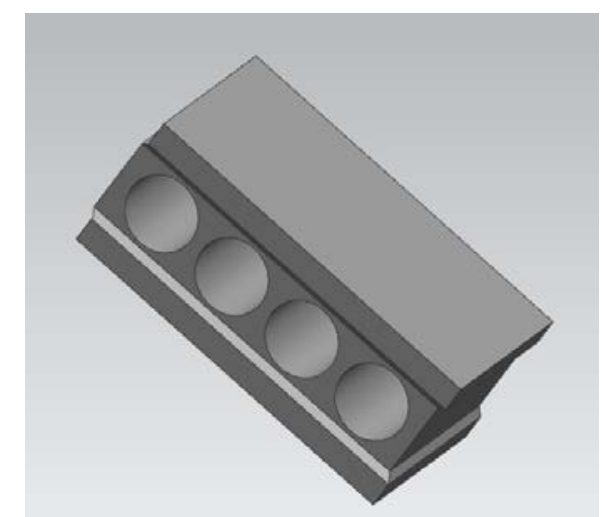

Fig. 1 Gypsum hollow block structure

\section{The working principle of gypsum hollow block molding machine}

In actual production process, most of the block molding machine adopts box injection mold molding, mechanical time, hydraulic ejector structure, to ensure product accuracy, and overcome the disadvantages of manual operation precision is poor, do the mechanization of small investment, easy operation, etc. Production system mainly includes the distribution feeder system, water supply system, mixing system, molding box main units, transmission system and hydraulic system, such as low noise. Its core part is the molding box host system, low noise hydraulic system refers to the set of horizontal and vertical set of hydraulic oil cylinder of the hydraulic oil cylinder of the hydraulic system. Work, distribution feeder system will allocate and transport to the mixing hopper in raw materials, water supply system adopts quantitative meter quantitative measurement was carried out on the water supply, mixing system make gesso and combination of water and of high speed stirring, the slippage mixing box for casting molding box respectively, block cooling forming longitudinal set after the start of the hydraulic oil cylinder, under the guidance of guide shaft, launch institutions put together have molding of gypsum block out box. Horizontal small hydraulic oil cylinder by the piston connecting rod set above the molding box cover and hardware reciprocating movement, ${ }^{[3]}$ the role of the cover body is when plaster casting cap body is pushed to the mould clamping box, plaster casting the gap along the cover body, after the plaster molding, transverse set small hydraulic cylinder pushing cover body remove the molding box, upper make gypsum brick automatic molding, without artificial plastic. The second function of the cover body is at the top of the block forming mold release is out after the plate under the action of horizontal set of hydraulic oil cylinder back to the upper part of the molding box box at the top, at the same time push the block mould transmission sent to the function of slide rail, to prepare for waiting for the next pouring. Can design according to the scale of production in the process of production of different production line, to meet the needs of different investors.

\section{3D design of gypsum hollow block molding machine}

Gypsum block molding machine is mainly composed of cover body, the molding box, launch mechanism, sliding seat, guide shaft, base, and other components of the hydraulic oil cylinder, hydraulic cylinder including transverse set small hydraulic cylinder and hydraulic cylinder longitudinal didn't buy.

\subsection{D design of molding box.}

The molding box adopts one module and four cavities structure, can be designed into a mold seven cavity structure, each box by convex template, concave template, two side plate, diaphragm, fixed under the molding box bottom and removable cover on body composition, mould box above the automatic control of convex device, do not need plastic by hand. The molding box materials of $40 \mathrm{cr}$ element chromium , mold walls painted with non-stick material, friction small, easy to die. As shown in figure 2, the actual production can be used multiple sets of mold box production cycles. 


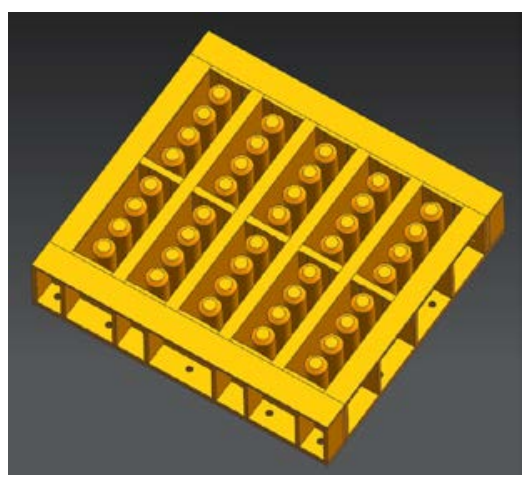

Fig. 2 Molding box stereogram

Convex templates, concave template for box, front/back plate is fixed by bolts on the bottom plate, mold is equipped with three parallel partition in the cabinet, will be divided into four cavity in the space, can make 4 pieces of gypsum block at the same time. Hollow axis symmetric set side by side in the cavity space, can be round, can also be a cone, square, etc. Hollow shaft is actually made up, middle and lower three parts: the lower part is used for fixed with a thread of short axis, middle hollow shaft, the upper is used for small hollow shaft wall cylinder, the hollow shaft end connections for welding. ${ }^{[4]}$ Easy to stripping, hollow shaft at the bottom of the upper size than small size $1 \mathrm{~mm}$ or so.

Molding box is trough, tenon active connection between floor and partition, molding box available partition compatibility, very easily in the production of different types of gypsum block, achieve multi-usage. Partition in such as the thickness of the corresponding production to $10 \mathrm{~mm}$ block, narrow partition corresponding to the block of production thickness is $120 \mathrm{~mm}$ wide diaphragm corresponding production for $80 \mathrm{~mm}$ thick blocks. Due to the nature of the gypsum itself, parting in order to reduce the mold walls and clapboard and gypsum block surface friction, chemical alloy on the surface of the walls and barrier layer, to reduce the friction coefficient, can save artificial brush demoulding agent process, improve work efficiency.

Gypsum hollow block combination molding unit USES infrared ray temperature controller, real-time monitoring the temperature of the mold cavity gypsum slurry pumping change, again into a control signal, reach the purpose of accurate control of gypsum block out of the mold time, ensure the quality of the product. Launch institutions of the push rod and its convex platform with a space between the gland, the push rod in a work with the edge of push-pull stress and elastic deformation occurs, the bottom of the push rod can within the scope of $360^{\circ}$ slip, thereby eliminating the push rod caused by push and pull stress under fatigue deformation, the balance of pushing on, fundamentally avoids the damage to molding box. ${ }^{[5]}$

\subsection{D design of launch institutions.}

Molding box launch institutions on the sliding seat, a total of four groups, by the push rod shaft, and the sliding plate of the push rod shaft connection, pushing plate, gasket, push down on the plate and so on, as shown in figure 3, It with sliding seat through screw fixation, set by vertical hydraulic cylinder pushing the gypsum block demoulding. Push rod through the upper molding box under the base plate and push plate connection, the push board is equipped with the push plate, and between the push plate and lower push plate on the site has made of PTFE plate gasket ${ }^{[6]}$, instead of traditional oil resistant rubber mat, has greatly reduced friction and oil cylinder thrust. Fixed a line at the side of the sliding seat position switch electromagnetic induction head, installed beside a electric induction line position switch board, to control the rise and fall of the launch of institutions.

\subsection{D design of the other components.}

Sliding seat through the screw connection with the launch institutions, sliding around four hole inner fixed guide bush, with four guide shaft asked gap respectively. In order to guarantee the stability of the movement with the height of the part size design is relatively larger, sliding seat for the whole casting, uniform wall thickness, at the bottom of the stiffener, accuracy is not high. Base parts for hollow structure, the main place vertical hydraulic cylinder, land under the foot bolt. 


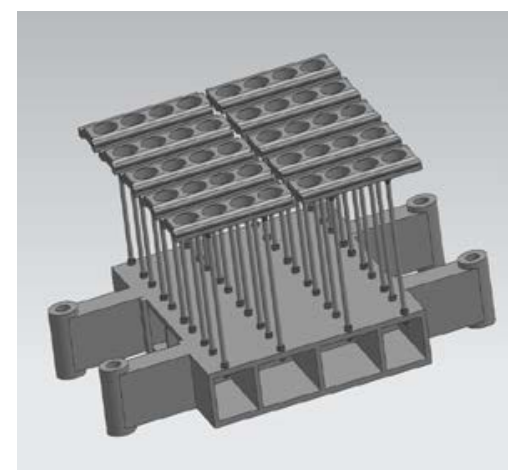

Fig. 3 Launch institutions

\section{3D assembly design of gypsum hollow block molding machine}

Gypsum block molding machine, after the completion of the main components of the three-dimensional design of assembly environment provided by UG, according to the product assembly sequence of complete parts and $3 \mathrm{~d}$ assembly of the machine, using the standard parts library can be transferred to the corresponding standard parts, and then complete the assembly of the machine. Again on this foundation for assembly parts between the static and dynamic interference check, if they do not have the design reasonable adjust and modify the design drawing, which can shorten the product manufacturing and assembly process time, reduce the cost of product assembly. Using UG own Animator plug-in animation function and function of the Motion of the COSMOS Motion simulation, can observe the decomposition of parts and assembly process, simulation block molding machine movement, to verify its working principle, assembly simulation results as shown in figure 4.



Fig. 4 3D assembly design of molding machine

\section{Conclusion}

After decades of development, our country block molding machine has become an important part of construction machinery, occupies certain proportion in the whole construction machinery industry, has formed a large-scale production capacity, the initial character can have a larger increase, but compared with foreign production there is still a certain gap, market competition is increasingly fierce $^{[7]}$. By UG in computer products, such as design, analysis, simulation and machining process, the design of can shorten product development cycle and satisfy the needs of small and medium-sized investors and product upgrading, make the enterprise can quickly response to market demand, and help to enhance the enterprise product development ability.

\section{References}

[1]Zhao Yongjun,Wang Desheng. The SolidWorks application in design of loader working device. Engineering machinery.(2010)NO.2,p.55-57. 
[2]Yang Guoxin,Wang Dingbiao. Mechanical parts based on SolidWorks virtual design technology. Coal mine machinery.(2007) NO.7,p.80-82.

[3]Gao Chenghui,Zhang Xiangyu. A combination of gypsum hollow block molding machine design and development. Building block and block building. (2007) NO.4,p.56-57.

[4]Cui Huanyong.Gypsum block molding machine research continuously. China building materials and equipment.

[5] Gao Chenghui,Zhang Xiangyu. The virtual prototype design of gypsum block molding machine. Mechanical engineering and automation. (2011)NO.5,p.85-87.

[6]Tan Cheng. Gesso Block Production Line Adaptive Control System Design. Master's thesis, Chongqing university, China 2012.p.35-38.

[7] K. K. SCHILLER, in “Mechanical properties of non metallicbrittle solids”, edited by W. H. Walton (Butterworth, London,1958) p. 35. 